\title{
Recombinant erythropoietin in clinical practice
}

\author{
T Ng, G Marx, T Littlewood, I Macdougall
}

Postgrad Med J 2003;79:367-376

The introduction of recombinant human erythropoietin (RHUEPO) has revolutionised the treatment of patients with anaemia of chronic renal disease. Clinical studies have demonstrated that RHuEPO is also useful in various non-uraemic conditions including haematological and oncological disorders, prematurity, HIV infection, and perioperative therapies. Besides highlighting both the historical and functional aspects of RHUEPO, this review discusses the applications of RHuEPO in clinical practice and the potential problems of RHuEPO treatment.

See end of article for authors' affiliations

Correspondence to: Dr Thomas Ng, Phase One Clinical Trials Unit Ltd, 119 Looseleigh Lane, Derriford Plymouth PL6 5HH, UK; tsfng@hotmail.com

Submitted 5 March 2002 Accepted

31 December 2002
$T$ he human body generates 2.5 million new red blood cells (RBCs) per second from the bone marrow to replenish the continuous removal of effete RBCs. The production of RBCs (erythropoiesis) is controlled by an intricate interaction between various humoral factors and cytokines. A specific cytokine, a sialoglycoprotein known as erythropoietin, which acts directly on certain RBC progenitors and precursors in the bone marrow, controls the proliferation, differentiation, and maturation of RBCs. The expression of erythropoietin is markedly increased in kidneys during hypoxic state, a condition mediated by the transcription factor HIF-1. The ultimate effect is to increase erythropoiesis in an attempt to maintain oxygen delivery to vital organs. This article provides an overview of erythropoietin on both historical and scientific aspects, followed by a discussion of its current and potential applications in clinical medicine.

\section{HISTORICAL PERSPECTIVE}

\section{From observation to discovery}

A positive correlation of hypoxia and anaemia with erythrocytosis has been noticed through clinical observations and experimentations since the late 19th century (table 1). Nevertheless, the purification of erythropoietin has been difficult because of technical limitations, heterogeneity of target cell population, and insufficient quantity of erythropoietin available for further analysis. A major breakthrough occurred in 1977 when Miyake and coworkers successfully purified and characterised human erythropoietin from urine of patients with aplastic anaemia. In 1985, two groups of investigators independently cloned the human erythropoietin gene with the identification of the corresponding nucleotide sequences.

\section{From discovery to clinical practice}

Before the availability of recombinant human erythropoietin (RHuEPO), the only treatment for patients with anaemia of chronic renal failure was blood transfusion. Unfortunately, blood transfusion had to be given regularly so as to maintain the haemoglobin level. Furthermore, various transfusion related problems, in particular iron overload, significantly compromised the management and outcome of renal patients. Based on the promising results on animal models, erythropoietin was considered a prime candidate as replacement therapy. As soon as RHuEPO was made available for human trial, a series of clinical studies were promptly conducted to assess its effectiveness in correcting anaemia of chronic renal disease. The initial results demonstrated that RHuEPO could restore the packed cell volume, abrogate the necessity of regular blood transfusion in patients requiring dialysis, and improve the overall wellbeing. ${ }^{2-4}$ The results of these trials were so impressive that RHuEPO was granted a licence as a therapeutic agent in 1988 for patients with anaemia of chronic renal failure, only three years after its discovery.

\section{RECOMBINANT HUMAN ERYTHROPOIETIN}

Structural and biological characteristics

Erythropoietin in blood is mainly of renal origin, with a small amount derived from the liver. The human erythropoietin gene is situated at chromosome $7 \mathrm{ql} 1-22$, consisting of five exons and four introns, which produces a post-transcriptional single polypeptide containing 193 amino acids. ${ }^{15}$ During the post-translational modification, glycosylation occurs with the addition of three $N$-linked (at Asn-24, Asn-38 and Asn-83) and one $O$-linked (at Ser-126) acidic oligosaccharides, the formation of two disulphide bonds at Cys-7 to Cys-161 and at Cys-29 to Cys-33, concomitant with the removal of the 27 amino acid hydrophobic secretory sequence. The Arg-166 at the $\mathrm{COOH}$ terminal is believed to be cleaved before the release of erythropoietin into the circulation, with the primary structure of a mature erythropoietin (and hence RHuEPO) containing 165 amino acids (fig 1). The molecular mass of the polypeptide backbone and the glycosylated form of erythropoietin is estimated to be $18 \mathrm{kDa}$ and $30 \mathrm{kDa}$ respectively. ${ }^{6}$ Circular dichroism spectral analysis has proposed that its secondary structure contains $50 \%$ of $\alpha$-helix moiety, with spatial arrangement of two $\alpha$-helical pairs running antiparallel

Abbreviations: G-CSF, granulocyte colony-stimulating factor; NESP, novel erythropoiesis stimulating protein; PRCA, pure red cell aplasia; RBCs, red blood cells; RHuEPO, recombinant human erythropoietin

Please note that packed cell volume is used in the text; this is equivalent to haematocrit 
Table 1 Historical perspective of erythropoietin (EPO), adapted from Jelkmann'

\begin{tabular}{|c|c|c|}
\hline Contributors & Contributions & Comment \\
\hline $\begin{array}{l}\text { Bert (1882) } \\
\text { Viault (1890) } \\
\text { Miescher (1890) }\end{array}$ & Observation of increased RBC count at high altitude & $\begin{array}{l}\text { A direct relationship of hypoxia to } R B C \text { count was } \\
\text { proposed }\end{array}$ \\
\hline Carnot and Deflandre (1906) & $\begin{array}{l}\text { Experiment on injected blood from anaemic rabbits to } \\
\text { donor rabbits causing a } 20 \%-40 \% \text { increased RBC in } \\
\text { blood }\end{array}$ & $\begin{array}{l}\text { Suggested a humoral factor "haemopoietine" to control } \\
\text { RBC production }\end{array}$ \\
\hline $\begin{array}{l}\text { Muller (1912) } \\
\text { Sandor (1932) } \\
\text { Krumdieck (1943) }\end{array}$ & $\begin{array}{l}\text { Experiment on injected blood from hypoxic rabbits to } \\
\text { donor rabbits causing an increased RBC in blood }\end{array}$ & $\begin{array}{l}\text { A direct relationship of hypoxia to } R B C \text { count } \\
\text { demonstrated }\end{array}$ \\
\hline Bonsdorff and Jalavisto (1948) & $\begin{array}{l}\text { Experiment on injected blood from hypoxic animals to } \\
\text { untreated animals causing a raised RBC production }\end{array}$ & $\begin{array}{l}\text { "Erythropoietin" was introduced to support the presence } \\
\text { and the transferability of the humoral factor }\end{array}$ \\
\hline $\begin{array}{l}\text { Reissmann (1950) } \\
\text { Ruhenstroth-Baver (1950) }\end{array}$ & $\begin{array}{l}\text { Increased RBC production on parabiotic animals when } \\
\text { hypoxia and anaemia was introduced in one of them }\end{array}$ & $\begin{array}{l}\text { A direct evidence of the presence of EPO to cause an } \\
\text { increase in RBC in hypoxia/anaemia }\end{array}$ \\
\hline Erslev (1953) & $\begin{array}{l}\text { Repeated infusing plasma from severely anaemic rabbits } \\
\text { to donor rabbits causing increased packed cell } \\
\text { volume/reticulocyte count }\end{array}$ & Predicted the therapeutic potential of EPO if purified \\
\hline Hodgson and Toha (1954) & $\begin{array}{l}\text { EPO activity isolated in urine and plasma of anaemic } \\
\text { rabbits }\end{array}$ & First to demonstrate EPO activity in urine \\
\hline $\begin{array}{l}\text { Stohlman et al (1954) } \\
\text { Schmid and Gilbersten (1955) }\end{array}$ & $\begin{array}{l}\text { Observations of RBC hyperplasia in bone marrow in } \\
\text { patients with patent ductus arteriosus }\end{array}$ & $\begin{array}{l}\text { Suggested hypoxia of lower part of body and increased } \\
\text { erythropoiesis }\end{array}$ \\
\hline Jacobson et al (1957) & No increase in RBC in nephrectomised animals & First to support EPO production of renal origin \\
\hline $\begin{array}{l}\text { Kuratowsha et al (1961) } \\
\text { Fisher and Birdwell (1961) }\end{array}$ & Detection of EPO activity in isolated perfused kidney & Confirmed kidney as a source of EPO production \\
\hline $\begin{array}{l}\text { Fischer et al (1965) } \\
\text { Frenkel et al (1968) }\end{array}$ & Localisation of EPO production to renal glomeruli & Suggested the regional secretion of EPO in kidney \\
\hline $\begin{array}{l}\text { Katz et al (1968) } \\
\text { Fried (1972) }\end{array}$ & Detection of EPO activity in liver & Confirmed liver as another source of EPO production \\
\hline Essers et al (1974) & $\begin{array}{l}\text { Suggested liver being insufficient to replace kidney for } \\
\text { EPO production }\end{array}$ & Supported kidney as the main source of EPO production \\
\hline Miyake et al (1977) & $\begin{array}{l}\text { Purification of EPO from urine in patients with aplastic } \\
\text { anaemia }\end{array}$ & First to isolate and characterise EPO \\
\hline $\begin{array}{l}\text { Anagnostone et al (1977) } \\
\text { Van Stone and Max (1979) } \\
\text { Eschbach et al (1984) }\end{array}$ & EPO on animals with anaemia of renal failure & $\begin{array}{l}\text { Demonstrated the effectiveness of EPO to correct } \\
\text { anaemia }\end{array}$ \\
\hline Jacobs et al (1985) & Cloning of EPO gene via "reverse genetics" & $\begin{array}{l}\text { Paved the way for industrial manufacturing of } \\
\text { recombinant EPO } \\
\text { Allowed sufficient quantity of EPO for clinical use }\end{array}$ \\
\hline
\end{tabular}

similar to that of growth hormone. The glycosylated (or sugar) moiety of erythropoietin has an important role in terms of biosynthesis, tertiary structure of the molecule, and in vivo biological activity.

The $N$-glycosylated moiety of RHuEPO has three main functional units: the main core, the branched portion and the ter- minal component, with each unit having a specific role (fig 2). The function of the $O$-glycosylated unit, a component constituting about 3\% of the total mass of RHuEPO, remains to be defined.

There are currently four different RHuEPOs: alpha, beta, delta, and omega. However, only EPO-alpha and EPO-beta are

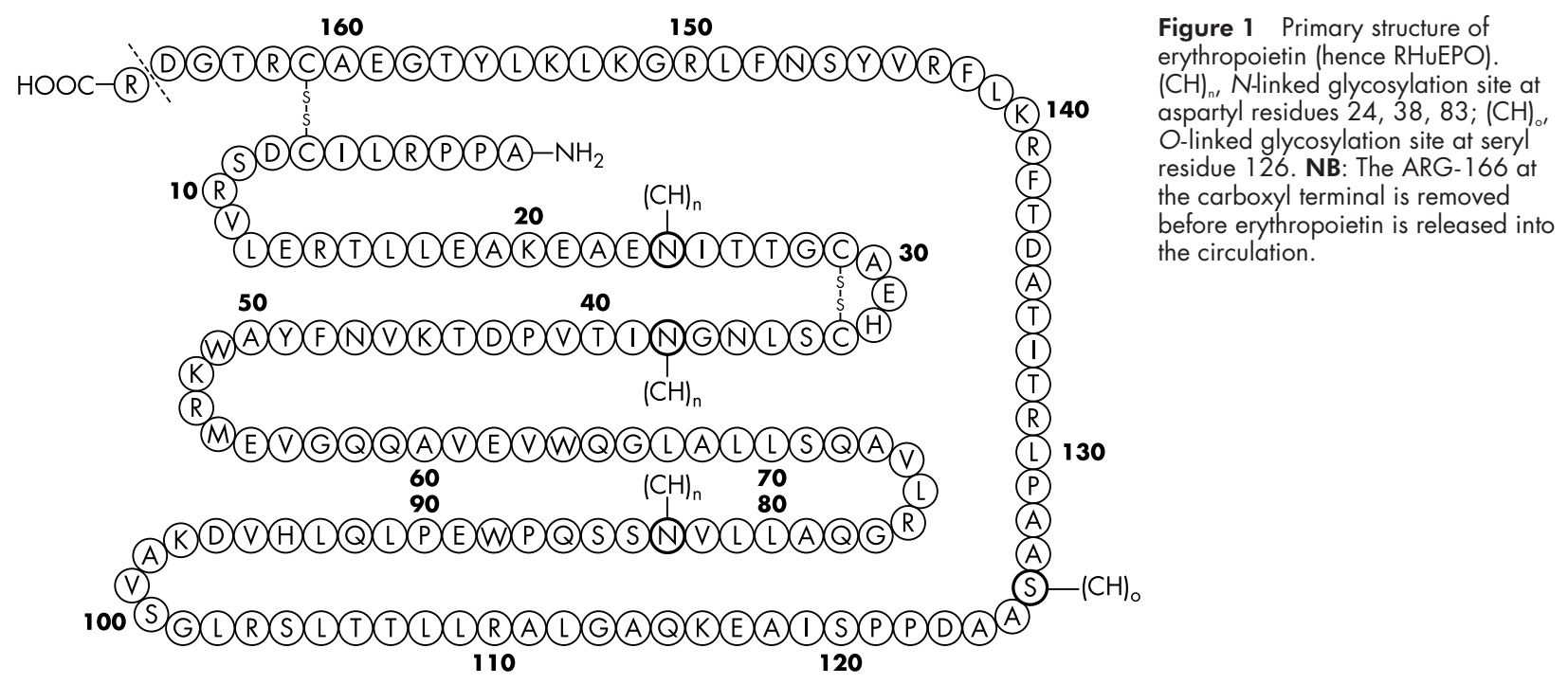




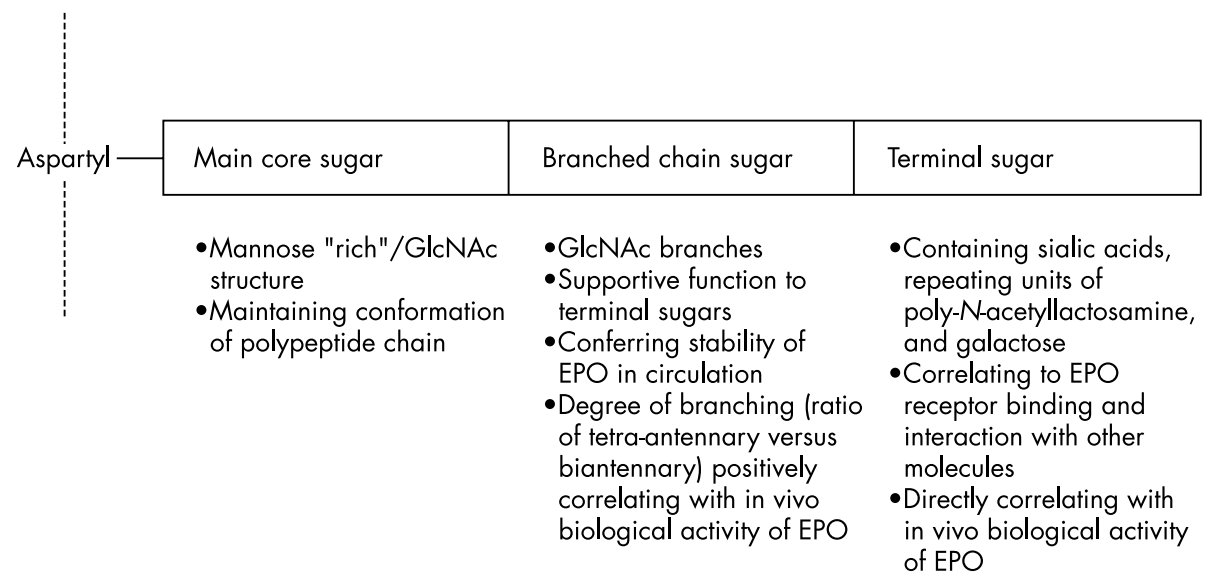

Figure 2 Outline of the functional units from $N$-glycosylation moiety of erythropoietin (EPO).

commercially available in the UK at the moment. Although these RHuEPOs act on the same erythropoietin receptor, there are some variations on the degree of glycosylation which lead to the differences in the pharmacokinetics and pharmacodynamics among the RhuEPOs.

\section{Modifications of RHuEPO}

As the $\mathrm{N}$-glycosylation confers the biological activity of $\mathrm{RHuEPO}$, an increase in the number of glycosylation sites may enhance its activity. A hyperglycosylated RHuEPO, known as NESP (novel erythropoiesis stimulating protein; Darbepoetinalpha) has recently been introduced. ${ }^{7}$ By using a process called "site mutagenesis", the polypeptide backbone of the RHuEPO is modified, leading to the creation of five $N$-glycosylation sites (compared with three in RHuEPO).

Compared with the RHuEPOs, NESP has a higher negative charge and a threefold longer half life. It requires a less frequent dosing schedule and produces a similar clinical outcome and safety profile as RHuEPOs in treating anaemia of chronic renal disease and of malignancy. ${ }^{8-10}$ The applicability of NESP in other clinical conditions is currently being evaluated.

Another strategy to enhance the biological activity of RHuEPO is to provide a "protective vehicle" so as to decrease the rate of elimination, thus prolonging the half life of RHuEPO. Methods such as microencapsulation and pegylation to RHuEPO are currently being assessed.

\section{Mechanism of action}

Erythropoietin is essential for the proliferation, differentiation, and maturation of RBCs in bone marrow. Moreover, erythropoietin is critical for the survival of RBC progenitors in

\section{Box 1: Key learning points}

- Human erythropoietin gene is encoded in chromosome 7 q $11-22$.

- Human erythropoietin is a sialoglycoprotein consisting of a 165 amino acid backbone with three $N$-glycosylation and one O-glycosylation sites.

- The $N$-glycosylation confers the biological activity of erythropoietin.

- RHuEPO has the same polypeptide backbone and has the equal number of glycosylation sites as the endogenous form.

- Differences in the glycosylation pattern confers some variations in both pharmacokinetic and pharmacodynamic profiles between the natural and the recombinant forms, and among the RHuEPOs.

- Erythropoietin is essentially for the proliferation, differentiation, and maturation of red blood cells.

- Recent studies have suggested that erythropoietin has antiinflammatory, antitumour, and neuroprotective properties. bone marrow and may also have immunomodulatory activity. ${ }^{112}$ Erythropoietin functions by binding to the erythropoietin receptor: a 72-78 kDa glycosylated and phosphorylated transmembrane polypeptide. The erythropoietin receptor is a member of the superfamily of cytokine receptors. $^{13}$ The number of erythropoietin receptors varies during RBC differentiation, with its peak presentation at the colony forming unit-erythroid/proerythroblastic stage and the level being undetectable at the reticulocytes. The binding of erythropoietin to its receptor results in homodimerisation of the receptor, followed by activation of several signal transduction pathways: JAK2/STAT5 system, G-protein (RAS), calcium channel, and kinases (fig 3).

\section{ADMINISTRATION OF RHUEPO}

\section{Route of administration}

Both intravenous and subcutaneous administrations are commonly used to deliver RHuEPO to renal patients. Clinical studies have demonstrated that the subcutaneous route offers a few advantages over intravenous administration. ${ }^{14}$ For instance, subcutaneous administration is more convenient as it does not require any venous access. When compared with

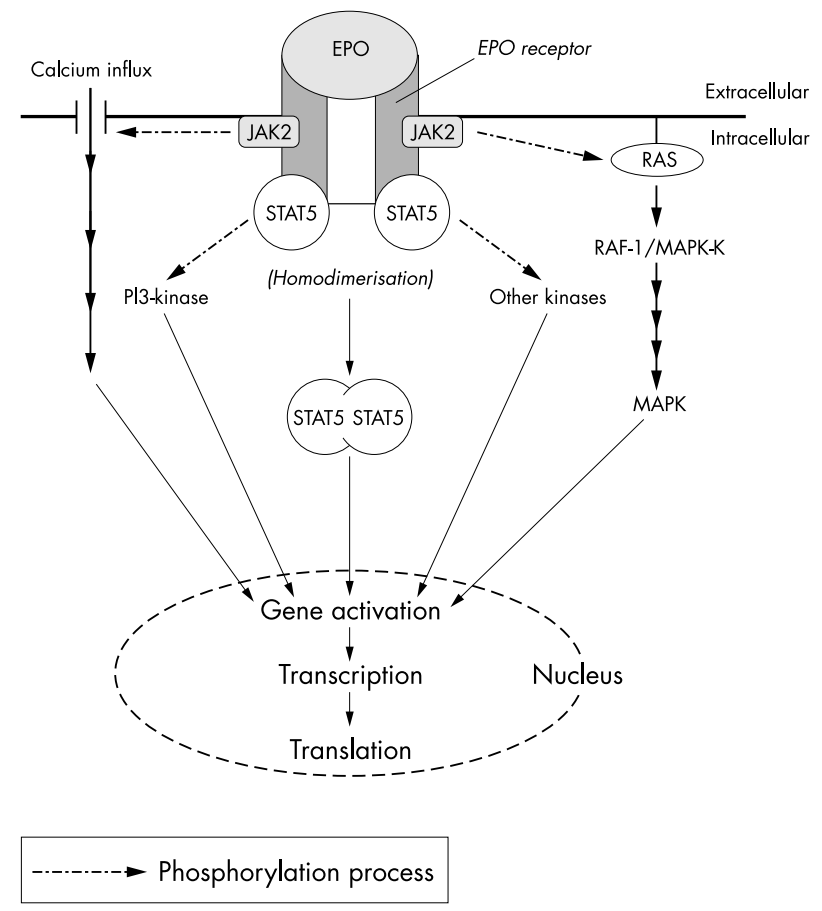

Figure 3 Simplistic view of the main signal transduction pathways activated by the erythropoietin (EPO) receptor. 


\section{Box 2: Clinical applications of RHuEPO}

- Replacement therapy (low endogenous erythropoietin level) in anaemia associated with:

(A) Chronic renal failure.

(B) Malignancy.

(C) Prematurity.

(D) HIV infection.

- Supportive therapy (to maintain/accelerate erythropoiesis ) in:

(A) Post-chemotherapy/post-radiotherapy.

(B) Post-transplantation.

- Augmentative therapy (increase haemoglobin above physiological level) in:

(A) Surgery.

(B) Situations where blood transfusion is refused/disallowed.

(C) Sport (potential abuse by athletes).

- To enhance autologous transfusion so as to maintain haemoglobin perioperatively.

- Other potential therapeutic applications:

(A) Anaemia associated with-autoimmune diseases, acute haemolysis, haemoglobinopathy.

(B) Acute renal failure.

(C) Critically ill patients.

(D) Neuroprotection.

(E) Congestive cardiac failure.

the intravenous route, subcutaneous RHuEPO administration significantly prolongs the increase of serum erythropoietin, thus sustaining the stimulation of erythropoiesis. Furthermore, up to $30 \%$ reduction in total weekly RHuEPO dosage on haemodialysis patients could be achieved to maintain the same haemoglobin level when switching intravenous to subcutaneous administration. Intraperitoneal administration of RHuEPO could be an alternative for the subcutaneous route but it is mainly applicable to renal patients receiving peritoneal dialysis. ${ }^{15}$ A larger dose of RHuEPO may be required to maintain the same haemoglobin level if RHuEPO has to be applied intraperitoneally.

As there is an increasing concern of pure red cell aplasia associated with subcutaneous EPO-alpha administration to renal patients, the Department of Health in UK recommends a change in the route of EPO-alpha administration from subcutaneous to intravenous. ${ }^{16}$ However, it remains uncertain whether similar measure will be applied to the other recombinant erythropoietins.

Outside the uraemic setting, both intravenous and subcutaneous RHuEPO have been employed but the subcutaneous route was used in the majority of the studies. However, there have been no studies to compare the efficacy of these routes.

\section{Frequency of administration}

Both intravenous and subcutaneous RHuEPO can be given from once daily to thrice, twice and once weekly in renal patients, depending on the clinical status of the patients. Similar differences in the frequency of RHuEPO administration have been applied in various non-uraemic conditions.

\section{CLINICAL APPLICATION OF RHUEPO}

RHuEPO has revolutionised the treatment of patients with anaemia of chronic renal failure. Moreover, RHuEPO has been shown to be effective in correcting anaemia associated with various non-uraemic conditions (box 2).

\section{Anaemia associated with chronic renal disease} Chronic renal failure on maintenance dialysis Patients with chronic renal failure have subnormal endogenous erythropoietin production. Clinical studies have shown that RHuEPO therapy corrects the anaemia of chronic renal failure, avoids blood transfusions and improves quality of life. ${ }^{17}$ Furthermore, it optimises a patient's haemodynamic status thus minimising the risk of progression to left ventricular hypertrophy and its associated mortality. Furthermore, it leads to an improvement of physical performance and cognitive function. ${ }^{18} 19$

\section{Patients at pre-dialysis stage}

A review published in 1995 suggested that pre-dialysis patients (and those with failing renal allografts) would gain no benefit from RHuEPO therapy if glomerular filtration rate was less than $15 \mathrm{ml} / \mathrm{min}$ but there would be a risk of accelerating to end stage renal failure. ${ }^{20}$ However, recent clinical studies have failed to confirm these negative effects of RHuEPO. $^{21}$ In fact, a meta-analysis on published data involving 12 randomised studies with more than 200 pre-dialysis patients during the period 1980-2001 has shown that early treatment with RHuEPO corrected anaemia, avoided blood transfusion, and improved the quality of life and exercise capacity. ${ }^{22}$ Although there was an increase in the requirement for antihypertensive therapy, no statistically significant increase in adverse events was otherwise found. There was also no evidence to suggest that RHuEPO therapy hastened a deterioration of renal function, though the authors conceded that the duration of RHuEPO therapy in most of the trials might not be long enough to confirm the benefit. Early application of RHuEPO has been shown to reduce the risk of cardiovascular events and the associated mortality. ${ }^{23}$ The addition of intravenous iron may decrease the dosage requirement of RHuEPO and could provide an additive and rapid effect in the correction of renal anaemia during the pre-dialysis period. $^{24}$

\section{Patients with renal transplant}

Unfortunately, there are insufficient clinical data to discuss in details the use of RHuEPO in the transplant setting. The avoidance of pre-transplant blood transfusion may impair the success of graft survival in patients receiving a cadaveric transplant, according to collaborative transplant studies. ${ }^{25}$ Furthermore, there are concerns that an increase in packed cell volume during renal transplant may predispose the patient to develop graft thrombosis and delayed graft function. ${ }^{26}{ }^{27}$ Muirhead reviewed the current data and highlighted several issues. ${ }^{28}$ Firstly, there was no convincing evidence of delayed graft function or graft thrombosis in patients previously treated with RHuEPO. Secondly, the use of RHuEPO might reduce allosensitisation as a result of random blood transfusion while allowing the benefits of graft survival from deliberate transfusion. Thirdly, the correction of posttransplant anaemia was enhanced and hastened by RHuEPO therapy. Fourthly, the effect of RHuEPO was minimal during an acute episode of graft rejection but its benefit resumed once successful treatment of the rejection episode had been achieved. Finally, despite the use of immunosuppressants, patients with failing grafts had a similar response to RHuEPO compared with those on dialysis. A recent study in Sweden has shown that pre-transplant correction of haemoglobin reduced the necessity of postoperative blood transfusion with no evidence of worsening the transplant outcome. ${ }^{29}$

\section{Anaemia of prematurity}

Neonates born prematurely (before 32 weeks of gestation) weighing less than $1300 \mathrm{~g}$ usually receive multiple blood transfusions to compensate for regular blood sampling required for intensive monitoring, along with a physiologically low serum level of erythropoietin. The principle of using RHuEPO in this setting, as replacement therapy, is to minimise the amount of blood transfused. Despite more than 12 clinical studies, involving more than a thousand premature 


\section{Box 3: Key learning points}

- RHuEPO corrects renal anaemia, avoids blood transfusion, and improves quality of life.

- In patients with chronic renal failure at pre-dialysis, RHuEPO may slow down disease progression and delay dialysis.

- RHuEPO therapy reduces cardiovascular events and the associated mortality in patients with chronic renal failure.

- There is no evidence that treatment with RHuEPO affects the outcome of renal transplant.

infants, no conclusion could be made as whether RHuEPO could definitively reduce the requirements for blood transfusion. ${ }^{30-33}$ Nevertheless, when the results from those infants were selectively analysed, it appeared that only those infants who received $\geqslant 600 \mathrm{IU} / \mathrm{kg} /$ week required less frequent blood transfusion. Economic analysis has shown that in those premature neonates who required transfusion, the use of RHuEPO would be cost effective and cost beneficial only if the administration of RHuEPO reduced the rate of transfusion..$^{34}$ It is interesting to note that preterm infants receiving RHuEPO may have a lower incidence of necrotising enterocolitis $^{36}$ and a reduction in the number of days requiring oxygen support. ${ }^{37}$ The latter result could be related to the increase in 2,3-diphosphoglycerate levels in RBCs causing a right shift in the oxygen dissociation curve. ${ }^{38}$

\section{Anaemia associated with malignancy}

Anaemia is a complication commonly encountered in malignancy, especially of haematological origin, either at presentation or during the course of treatment. Anaemia of chronic disease, a condition characterised by disordered iron metabolism, shortened RBC half life and inefficient erythropoiesis, is the major contributor to cancer anaemia. ${ }^{39}$ Besides impoverishing the patient's quality of life, anaemia at diagnosis is a poor prognostic factor (especially in lymphoproliferative disorders) and may affect the outcome of radiotherapy treatment. Although blood transfusion remains the mainstay of treatment for symptomatic anaemia, it is associated with various problems. Firstly, oxygen delivery by preserved RBCs decreases after one week of storage as a result of decrease in 2,3-diphosphoglycerate, together with other physical and biochemical changes in RBCs. ${ }^{40}$ Secondly, the "preservation injury" on stored RBCs reduces RBC deformability and increases haemoglobin affinity for oxygen. It has been demonstrated that transfusion of stored blood, unless freshly prepared, may not improve and may probably worsen tissue oxygen consumption in critical conditions. ${ }^{41}{ }^{42}$ Lastly, despite a recent prospective study conducted by the British Transfusion Service, which reported a negligible risk of contracting blood borne infection, ${ }^{43}$ there are still some inherent risks of transfusion that cause unresolved concerns (table 2). Whether the recent adoption of universal leucodepletion in the UK on all blood donations will minimise the overall incidence of leucocyte-mediated immunological and infective events remains to be seen.

More than half of cancer patients have a low serum level of erythropoietin. ${ }^{48}$ RHuEPO has been employed in correcting the anaemia, either as supportive or preventive treatment, with an excellent safety profile. Interestingly, RHuEPO has recently been shown capable to induce apoptosis in myeloma cell culture, suggesting its antitumour activity. ${ }^{49}$

\section{Solid tumour}

In general, anaemia could be corrected in about $50 \%$ of patients when RHuEPO is given after chemotherapy. A higher proportion of anaemia correction could be achieved in patients who received platinum based chemotherapy. ${ }^{50} 51$
When RHuEPO is applied before chemotherapy, it prevents the decline in haemoglobin and decreases the requirement of blood transfusion during the course of chemotherapy. ${ }^{52} 53$ Nowrousian has suggested that when given subcutaneously at a dose of $150 \mathrm{U} / \mathrm{kg}$ three times a week in selected patients, RHuEPO can produce a response rate of up to $80 \% .{ }^{54}$ In a large prospective community study, the use of RHuEPO increased the functional capacity and the quality of life of patients. It also improved the level of haemoglobin and minimised blood transfusion requirements..$^{55}$ The positive outcomes correlated with the haemoglobin level but were independent of the tumour response.

Recent clinical studies have demonstrated that a normal or near normal level of haemoglobin before radiotherapy with or without chemotherapy could improve the treatment outcome. ${ }^{56}$ In a recent multicentre, randomised study in patients with pelvic malignancies, the addition of RHuEPO to the treatment course of radiotherapy improved both treatment response rate and patients' survival. ${ }^{57}$ Furthermore, a recent analysis of two large scale studies involving 4382 patients, has revealed that patients with solid tumours receiving RHuEPO had a significant improvement in quality of life occurring between haemoglobin levels from 80 to $140 \mathrm{~g} / \mathrm{l}^{58} \mathrm{The}$ most noticeable benefit, from an incremental increase in haemoglobin, occurred when there was a change in haemoglobin from 110 to $120 \mathrm{~g} / \mathrm{l}$.

\section{Haematological malignancy/pre-leukaemic stem cell disorder}

Multiple myeloma, lymphoproliferative diseases, and chronic lymphocytic leukaemia are those haematological disorders that benefit significantly from RHuEPO therapy, with an average response rate of $60 \%$. Whether RHuEPO is given as supportive (post-chemotherapy), preventive (pre-treatment) or maintenance (optimisation of haemoglobin while not on treatment) therapy, it increases the haemoglobin and minimises the requirement for blood transfusions..$^{59-62}$ However, a delay in treatment response of up to four weeks may occur.

Although the response rate of myelodysplastic syndrome to RHuEPO therapy is approximately $20 \%$, the addition of granulocyte colony-stimulating factor (G-CSF) has been shown to improve the response. The response to the combined cytokine treatment is not significantly correlated with the type of myelodysplastic syndrome, age or sex of the patient. Treatment is usually well tolerated and there is no evidence of an increased risk of leukaemic transformation. ${ }^{63}$ HellstromLindberg and coworkers proposed a model to predict the response of anaemia to combined RHuEPO and G-CSF. ${ }^{64}$ The authors introduced a scoring system based on two main criteria: the level of serum erythropoietin before treatment and the transfusion requirement per month. Using these criteria, three response groups were generated: high, intermediate, and low with the corresponding predicted response rate to RHuEPO therapy of $74 \%, 23 \%$, and $7 \%$ respectively. A long term response could be achieved in up to one third of patients and a dose of $20000 \mathrm{U} /$ week appeared to be an effective maintenance dose of RHuEPO treatment. ${ }^{65}$

\section{Anaemia associated with bone marrow/stem cell transplantation}

"Conditioning" using intensive chemotherapy with or without radiotherapy (myeloablative treatment) before transplantation induces a state of pancytopenia which requires regular blood product support until bone marrow/stem cells have been fully engrafted. The frequency of blood transfusion requirement has been estimated at 11/patient $/ 50 \mathrm{~kg}$ body weight within the first two months after transplant. This may be further increased if complications such as immune haemolysis, graft-versus-host disease, or bleeding occur. ${ }^{66}$ Impaired production of erythropoietin (for example, renal damage due to chemotherapy, inhibition of erythropoietin secretion by amphotericin treatment) and a blunted response to erythropoietin (for 
Table 2 Problems associated with allogeneic blood transfusion ${ }^{44-47}$

\begin{tabular}{|c|c|c|}
\hline Problems & $\begin{array}{l}\text { Estimated risk (per unit of } \\
\text { blood transfused)* }\end{array}$ & Pathological basis \\
\hline \multicolumn{3}{|l|}{ Immediate (within 24 hours) } \\
\hline (1) Acute haemolysis (potentially fatal) & $1: 6000-800000$ & $\mathrm{ABO}$ incompatibility \\
\hline (2) Bacterial infection (potentially fatal) & $1: 435-12500$ & Bacterial contamination \\
\hline \multicolumn{3}{|l|}{ (3) Other immune related reaction: } \\
\hline Febrile non-haemolytic transfusion reaction & $1: 200$ & Sensitivity to WBC \\
\hline Transfusion related acute lung injury ( $20 \%$ mortality) & $1: 5000-10000$ & $\begin{array}{l}\text { Donor lymphocytes against recipient WBC with } \\
\text { shared HLA haplotypes }\end{array}$ \\
\hline (4) Volume overload & $1: 100-10000$ & $\begin{array}{l}\text { Too rapid transfusion or in patients with pre- } \\
\text { existing cardiac failure }\end{array}$ \\
\hline \multicolumn{3}{|l|}{ Short term (within 4 days) } \\
\hline (1) Volume overload & As previously stated & As previously stated \\
\hline (2) Haemolysis (usually low grade but progressive) & $1: 183-4000$ & $\begin{array}{l}\text { Delayed antibody reaction to } R B C \text { antigen (other } \\
\text { than } A B O \text { ); low grade bacterial infection }\end{array}$ \\
\hline (3) RBC antigen sensitisation (allosensitisation) & $1: 100$ & RBC antigen (other than $A B O$ ) incompatibility \\
\hline \multicolumn{3}{|l|}{ Intermediate (within 14 days) } \\
\hline (1) RBC antigen sensitisation (allosensitisation) & As previously stated & As previously stated \\
\hline (2) Haemolysis ( usually low grade but progressive) & As previously stated & $\begin{array}{l}\text { Delayed antibody reaction to } R B C \text { antigen (other } \\
\text { than } A B O \text { ) }\end{array}$ \\
\hline (3) Increased risk of postoperative infection & N/A & Immunomodulation \\
\hline (4) Post-transfusion purpura & Rare $(1: 200000)$ & $\begin{array}{l}\text { Passive transfer of HPA platelet antibody from HPA } \\
\text { antigen negative donor }\end{array}$ \\
\hline \multicolumn{3}{|l|}{ Long term (>14 days) } \\
\hline (1) Increasing difficulty in cross matching & N/A & $\begin{array}{l}\text { Previous allosensitisation of RBC antigen as a result } \\
\text { of repeated transfusion }\end{array}$ \\
\hline (2) Secondary iron overload & N/A & Due to repeated blood transfusion \\
\hline (3) Transfusion related graft-versus-host disease (potentially fatal) & Rare $(1: 500000)$ & $\begin{array}{l}\text { Donor immunoreactive lymphocytes against } \\
\text { recipient HLA antigens (HLA incompatibility) }\end{array}$ \\
\hline (4) Seroconversion of cytomegalovirus & $1: 14-41$ & Passive transfer of CMV infected WBCs \\
\hline (5) Increased risk of malignancy & ( $\times 2$ over life time) & ? Immunomodulation \\
\hline (6) New variant CJD & N/A & ? WBC mediated \\
\hline (7) Hepatitides B and C & Rare $(1: 200000)$ & Infected blood \\
\hline (8) HIV & Very rare $(<1: 3000000)$ & Infected blood \\
\hline
\end{tabular}

*Data obtained from various sources including non-filtered to leucodepleted blood.

CJD, Creutzfeldt-Jakob disease; CMV, cytomegalovirus; HPA, human platelet antigen; N/A, not available; WBC, white blood cell.

\section{Box 4: Key learning points}

- Anaemia of chronic disease is the main cause of cancer anaemia.

- RHuEPO therapy corrects $50 \%$ of cancer anaemia in general.

- Treatment with RHuEPO minimises the transfusion requirement.

- Quality of life in cancer patients is enhanced with RHuEPO treatment.

- RHuEPO therapy improves both treatment outcome and survival of cancer patients.

example, tumour necrosis factors produced during inflammation) could also contribute to post-transplant anaemia. Klaesson reviewed 17 clinical trials of bone marrow/stem cell transplantation (11 allogeneic; seven autologous) using intravenous RHuEPO (range $50 \mathrm{U} / \mathrm{kg}$ three times a day to 500 U/kg once a day for a 28-30 day period), with or without GCSF/granulocyte-macrophage-CSF. ${ }^{67}$ The author concluded that in patients receiving an allogeneic transplant, the use of RHuEPO could expedite erythroid engraftment and augment the level of haemoglobin. Furthermore, RHuEPO therapy could reduce the requirements for blood transfusion and hasten the time to transfusion independence. The efficacy of RHuEPO was also observed in late-onset anaemia due to graft-versus-host-disease or infection and immune haemolysis secondary to bone marrow/stem cell ABO incompatibility. Transplant donors pre-treated with RHuEPO (and iron supplement) did not require autologous blood transfusions. However, these benefits from RHuEPO treatment were not found in patients receiving an autologous transplant. The author has argued that despite these benefits, RHuEPO therapy costs an extra US\$2000 (about $£ 1334$ ) to avoid five extra units of blood to be transfused. In the UK, the cost may be offset by the subcutaneous RHuEPO administration and by the expense incurred on the universal leucodepletion of blood products. The increased popularity of non-myeloablative approach of bone marrow/stem cell transplant (minitransplant) may reduce the dosage requirement for RHuEPO. Further studies in this area are warranted.

\section{Anaemia associated with surgery}

Autologous transfusion, either as pre-donation (haemoglobin augmented with RHuEPO therapy) or as a blood salvage procedure during the operation, has been shown to be effective in certain operations. ${ }^{68}$ Nevertheless, autologous transfusion is not universally adopted in the UK and is expensive to implement. There is increasing evidence that RHuEPO can minimise blood transfusion in patients whose surgical procedure, for example cardiothoracic surgery or orthopaedic surgery, may cause up to a $20 \%$ loss of total blood volume ${ }^{69}{ }^{70}$ Furthermore, a recent study has demonstrated that in patients who were not eligible for autologous donation, a low dose of RHuEPO (150 $\mathrm{IU} / \mathrm{kg} /$ week) given 3-4 weeks before surgery reduced the blood transfusion requirement by nearly $50 \%{ }^{71}$

\section{Anaemia associated with HIV infection}

Up to two thirds of patients suffering from AIDS have anaemia, particularly those who are receiving zidovudine therapy. Treatment with RHuEPO, given either as a weekly dose (24 000-48 $000 \mathrm{U}$ ) or as a thrice weekly administration (100-200 U/kg), corrects anaemia, improves the patient's quality of life when baseline serum erythropoietin is $<500$ $\mathrm{mU} / \mathrm{ml}$, and improves survival. ${ }^{72-74}$ It has been suggested that the target haemoglobin should be maintained at $120 \mathrm{~g} / \mathrm{l}$ and $110 \mathrm{~g} / \mathrm{l}$ in males and females respectively. ${ }^{75}$ 


\section{OTHER POTENTIAL APPLICATIONS FOR RHUEPO \\ Autoimmune diseases}

Anaemia is common in rheumatological disorders, in particular rheumatoid arthritis. This is usually due to anaemia of chronic disease. Pure red cell aplasia, a rare but recognised complication of systemic lupus erythematous, could further exacerbate the anaemia. Other complications, such as chronic blood loss and malabsorption, are particularly prominent in inflammatory bowel diseases. The RHuEPO therapy has been shown to be effective in controlling these immune associated conditions. ${ }^{76-78}$

\section{Haemolysis}

The fall of haemoglobin as a result of RBC disorders, such as hereditary spherocytosis and haemoglobinopathies, or due to mechanical damage, such as cardiac valve dysfunction, can be controlled, at least temporarily, by the use of RHuEPO. ${ }^{79-81}$

\section{Acute renal failure}

In murine model of ischaemic acute renal failure, RHuEPO has been found capable to rapidly reverse the associated anaemia, accelerate functional recovery of the kidneys, and reduce mortality ${ }^{82}{ }^{83}$ Furthermore, RHuEPO may offer renoprotection in cisplatin induced acute renal failure and accelerates renal recovery. ${ }^{84}{ }^{85}$ Clinical studies to evaluate these important findings are warranted.

\section{Critically ill patients}

Patients in intensive care regularly require blood transfusion. Patients who are anaemic have an inappropriately low endogenous serum erythropoietin..$^{86} \mathrm{~A}$ recent prospective, multicentre, randomised study has demonstrated that RHuEPO therapy (initiated on $300 \mathrm{U} / \mathrm{kg}$ subcutaneously from day 3 for five consecutive days followed by an alternate day administration until the packed cell volume reached 38\%) reduced the requirement of blood transfusion by $50 \%$. Furthermore, there were no significant differences in both mortality and frequency of adverse events when compared with the control groups. ${ }^{87}$

\section{Neuroprotection}

Based on the results from murine model, the use of RHuEPO has been shown to limit the degree of ischaemic cerebral damage and spinal cord injury, together with expediting neurological recovery. ${ }^{88} 89$

Ehrenreich and coworkers have demonstrated the beneficial effects of administering RHuEPO in patients with acute ischaemic stroke. ${ }^{90}$ When given within five hours of onset of symptoms, intravenous RHuEPO (33000 IU daily for three days) was associated with a significant improvement in both functional activity and clinical outcome. When compared with the controls, the RHuEPO group had a strong trend on reduction in infarct size. Furthermore, no safety concerns were identified in the study. The results of the study offer potential value to patients in whom thrombolytic therapy is contraindicated. Whether RHuEPO could add value to the thrombolytic therapy in treating acute ischaemic stroke remains to be determined.

\section{Congestive cardiac failure}

Although anaemia is commonly encountered in congestive cardiac failure, its clinical significance is less appreciated. Silverberg and colleagues have correlated the clinical importance of anaemia in congestive cardiac failure. ${ }^{91}$ Firstly, the severity of anaemia increases with the worsening of congestive cardiac failure. Secondly, anaemia is an independent risk factor for cardiac death (nearly doubling the mortality rate). Thirdly, many causes of anaemia may coexist in this setting. For instance, iron deficiency secondary to poor nutrition; suboptimal erythropoietin activity due to production deficiency (for example, in chronic renal failure), associated treatment (for

\section{Box 5: Key learning points}

- RHuEPO therapy significantly reduces the transfusion requirement in both surgical and critically ill patients.

- Treatment with RHuEPO corrects anaemia associated with prematurity.

- RHuEPO therapy corrects anaemia and improves both quality of life and survival in patients with HIV infection.

- With cautious approach, RHuEPO can be used as an alternative to blood transfusion.

- Within the oncology setting, as RHuEPO therapy is expensive, it should be targeted on the subgroup likely to respond to the treatment.

- Potential application of RHuEPO to other clinical areas is actively pursued.

- RHuEPO therapy is generally safe and well tolerated.

example, angiotensin converting enzyme inhibitor), proteinuria (loss of erythropoietin) and increased activity of cytokines (for example, tumour necrosis factor- $\alpha$ ), together with haemodilution due to an increased plasma volume, which all contribute to anaemia. Fourthly, the anaemia itself could lead to prolonged activation of the renin-angiotensin-aldosterone system, thus exacerbating the congestive cardiac failure. Renal function then deteriorates and the production of erythropoietin is reduced. Erythropoietin activity is further impaired due to an increased secretion of cytokines triggered by congestive cardiac failure. As a consequence, the anaemia is worsened and a vicious cycle is created (Cardio-Renal-Anaemia syndrome). Fifthly, the anaemia in congestive cardiac failure could be safely corrected by subcutaneous RHuEPO and intravenous iron, which results in ameliorating congestive cardiac failure, preventing the progression of chronic renal failure, reducing diuretic doses and hospitalisation, together with improving the quality of life. Finally, the authors have emphasised that the treatment of anaemia should be initiated early and the success of treatment requires a close cooperation between cardiologists and nephrologists.

The benefit of early anaemia treatment using subcutaneous RHuEPO (with intravenous iron) is supported by the results of a recent study involving both type 2 diabetes and non-diabetes suffered from moderate to severe resistant congestive cardiac failure. ${ }^{92}$ In addition to a significant improvement in both functional status and cardiac function, there was a marked reduction in hospitalisation, together with stabilisation of renal function.

\section{AVOIDANCE OF BLOOD TRANSFUSION}

Blood transfusion remains the mainstay for treating patients suffered from symptomatic anaemia. However, patients may refuse a blood transfusion because of personal preferences or religious reasons. Sometimes, due to the previous allosensitisation and the presence of rare RBC antigens, the procurement for sufficient units of compatible blood may not be feasible. Furthermore, the impending changes issued by the Department of Health on blood transfusion, including revision of blood donor eligibility and blood testing on new variant Creutzfeldt-Jakob disease, will severely affect the blood donor pool and further limit the availability of blood supply. ${ }^{93}$

Although RHuEPO therapy has been shown to be a suitable alternative for blood transfusion, the treatment is only applicable in non-acute or planned situations. In general, it takes at least 72 hours to detect a reticulocyte response and at least 10-14 days for any significant rise in haemoglobin. Other potential candidates of blood substitutes, for example recombinant haemoglobin, polymerised haemoglobin and perfluorocarbons, are currently being assessed.

In Jehovah's Witnesses, RHuEPO has been successfully employed to avoid blood transfusion in various surgical 
Box 6: Contributing factors which affects the response to RHuEPO

Therapeutic

- Non-compliance.

- Suboptimal treatment: "faulty" delivery, incorrect dosage of RHuEPO, under-dialysis.

Pathological

- Iron deficiency.

- B12/folate deficiency.

- Infection.

- Inflammation.

- Blood loss: haemorrhage, haemolysis (intravascular/ extravascular).

- Metabolic disorder-for example, secondary hyperparathyroidism.

- Extensive bone marrow involvement: malignant cells, fibrosis, aluminium toxicity.

- Erythropoietin antibody \pm pure red cell aplasia.

procedures. ${ }^{94}{ }^{95}$ In view of a normal/raised endogenous erythropoietin level, an initial high dose of RHuEPO $(300 \mathrm{U} / \mathrm{kg}$ three times a week), together with intravenous iron supplement may be required..$^{96}$

\section{MISUSE OF RHUEPO ("BLOOD DOPING")}

An increase in haemoglobin above normal physiological values has been shown to enhance physical endurance presumably as a result of increased oxygenation in the blood. ${ }^{97}$ As some athletes use RHuEPO as a "performance enhancer", the International Olympic Committee has classified RHuEPO as a banned substance. Unfortunately, the detection of RHuEPO still remains difficult. Although various parameters have been employed (for example, reticulocyte haemoglobin, serum transferrin receptor, packed cell volume, etc), none of them are reliable or reasonably sensitive. The use of electrophoretic analysis on the glycosylation pattern of serum erythropoietin may be able to distinguish the endogenous from the recombinant form. However, the procedure is time consuming and is not universally available.

\section{UNSATISFACTORY RESPONSE TO RHUEPO TREATMENT}

Failure to respond to RHuEPO therapy could be defined as haemoglobin increases of $<10 \mathrm{~g} / \mathrm{l}$ after a four week standard dosage treatment. However, the definition of resistance to RHuEPO therapy varies among different settings. For instance, in renal anaemia, resistance to RHuEPO is defined by a failure to attain the target haemoglobin while receiving $>300 \mathrm{IU} / \mathrm{kg} /$ week or a continued need for such a dosage to maintain the target haemoglobin. In the haematology/ oncology setting, resistance to RHuEPO therapy is regarded as no satisfactory haemoglobin increase of $>10 \mathrm{~g} / \mathrm{l}$ despite a four week high dose RHuEPO (900 IU/kg/week) therapy, in patients previously failed on a four week treatment with standard dosage (450 IU/kg/week). Nevertheless, it is important that other possible contributing factors are excluded (box $6)$.

\section{OPTIMISATION OF RHUEPO TREATMENT}

In renal patients requiring dialysis, the concomitant use of intravenous iron, either intermittently or continuously, has been shown to reduce the RHuEPO dosage requirement to maintain the target haemoglobin. ${ }^{148}$ Other measures, such as high dose intravenous ascorbic acid, high dose intravenous carnitine, growth factors, and cytokines (for example, insulinlike growth factor-1, interleukin-3) have demonstrated some success to optimise RHuEPO therapy in renal patients. ${ }^{14}$
Box 7: Predictive factors for response to RHUEPO therapy

RBC parameters

- Haemoglobin level.

- Packed cell volume.

- Reticulocyte: absolute count, relative percentage, mean haemoglobin.

- Percentage of hypochromic RBCs.

Cytokines

- Serum erythropoietin level.

- Tumour necrosis factor- $\alpha$.

Iron status

- Serum ferritin level.

- Transferrin saturation.

- Soluble transferrin receptor.

Box 8: Clinical features of PRCA associated with RHuEPO treatment ${ }^{99-101}$

- A very rare complication of RHuEPO treatment.

- Associated with patients chronic renal failure requiring dialysis.

- Persistent or worsening anaemia despite maximised RHuEPO therapy.

- Median age of presentation: 61 years.

- Male to female ratio: 2 to 1 .

- Median duration of RHuEPO treatment to time of diagnosis: seven months.

- Aetiology: unknown.

- Associated with neutralising antierythropoietin antibody directed against the polypeptide backbone (rather than the glycosylated moiety).

Despite the initiation RHuEPO treatment dosage in malignancy being five times higher than that of renal, the average response is only 50\% (compared with $>90 \%$ in patients with chronic renal failure). Furthermore, RHuEPO therapy is expensive and will further impose pressure on the restricted hospital funding. As a consequence, guidelines with emphasis on factors such as patient selection, type of chemotherapy employed, and utilisation of specific predictive factors (box 7) are required to rationalise the use of RHuEPO. These guidelines will assist in providing treatment to appropriate patients and minimise the economic impact on widespread use of RHuEPO.

As RHuEPO therapy accelerates erythropoiesis, a functional iron deficiency (a condition in which the iron store in the body remains normal but the rate of iron supply fails to keep pace with the rate of accelerated utilisation) will ensue. Therefore, iron supplementation is strongly recommended during RHUEPO treatment and the iron status should be regularly monitored.

\section{COMPLICATIONS OF RHUEPO TREATMENT}

The commonest side effect of RHuEPO therapy is "flu-like" illness. It is generally mild, subsides within 24 hours, and responds well on simple supportive treatment. Hypertension and thrombosis have also been reported. They are associated with a rapid rise in haemoglobin/packed cell volume during RHuEPO treatment. Clinical vigilance will minimise the occurrence of these problems. Other side effects such as allergic/anaphylactoid reactions, seizure, hyperkalaemia, and thrombocytosis have been rarely reported.

A serious but very rare complication, known as pure red cell aplasia (PRCA), has recently been reported in renal patients receiving RHuEPO treatment (box 8). The management of 
PRCA associated with RHuEPO therapy includes confirming PRCA by bone marrow biopsy, discontinuing the RHuEPO, initiating immunosuppressants with or without intravenous immunoglobulins, and blood support if required..$^{100-102}$ It is important to report the complication to the Committee on Safety of Medicine (via the yellow card system) and to the manufacturer.

Although PRCA is a very rare complication associated with RHuEPO treatment, it has significant implications concerning the use of RHuEPO in clinical practice. Regular assessment on the clinical status of the patients, together with monitoring the haemoglobin level and the reticulocyte count during RHuEPO therapy, is therefore strongly recommended.

\section{CONCLUSION}

The use of RHuEPO has undoubtedly altered the traditional management of renal anaemia. Its therapeutic benefit has been explored in other clinical areas. Nevertheless, RHuEPO is an expensive treatment and not every patient will benefit from it. Any contributory and treatable causes of anaemia must be excluded before the initiation of RHuEPO therapy. In malignancy, it is advisable that RHuEPO therapy is targeted to the subgroup of patients who is most likely to respond. Iron supplementation is recommended as RHuEPO therapy accelerates erythropoiesis causing a functional iron deficiency. Based on the effect of RHuEPO on its receptor, investigations have been focused on searching for alternatives to enhance and stimulate erythropoiesis. In the future, we are likely to envisage new development which optimises and maximises erythropoiesis, thus shifting the paradigm of anaemia management.

\section{Authors' affiliations}

T Ng, Phase One Clinical Trials Unit Ltd, Plymouth, UK

G Marx, Sydney Haematology Oncology Clinic, Hornsby, New South

Wales, Australia

T Littlewood, Department of Haematology, John Radcliff Hospital,

Oxford, UK

I Macdougall, Department of Renal Medicine, King's College Hospital

(Dulwich), London, UK

\section{REFERENCES}

1 Jelkmann W. Erythropoietin: structure, control of production and function. Physiol Rev 1992;72:449-89.

2 Winearls CG, Oliver DO, Pippard M, et al. Effects of human erythropoietin derived from recombinant DNA on the anaemia of patients maintained by chronic haemodialysis. Lancet 1986;ii: $1175-8$.

3 Eschbach JW, Egrie JC, Downing MR, et al. Correction of the anaemia of end-stage renal disease with recombinant human erythropoietin: results of a combined phase I and II clinical trial. N Engl J Med 1987:316:73-8

4 Eschbach JW, Abdulhadi MH, Browne JK, et al. Recombinant human erythropoietin in anemic patient with end-stage renal disease. Results of a phase III multicenter clinical trial. Ann Intern Med 1989;111:9921000 .

5 Law ML, Cai GY, Lin FK, et al. Chromosomal assignment of the human erythropoietin gene and its DNA polymorphism. Proc Natl Acad Sci U S A 1986:83:6920-4

6 Inove N, Takeuchi $M$, Ohashi $H$, et al. The production of recombinant human erythropoietin. Biotechnology Annual Review 1995;1:297-313.

7 Macdougall IC. An overview of the efficacy and safety of novel erythropoiesis stimulating protein (NESP). Nephrol Dial Transplant 2001:16(suppl 3):14-21.

8 Locatelli F, Olivares J, Walker R, et al. Novel erythropoiesis stimulating protein for the treatment of anaemia in chronic renal insufficiency. Kidney Int 2001;60;2:741-7.

9 Glaspy J, Jadeja JS, Justice G, et al. A dose-finding and safety study of novel erythropoiesis stimulating protein (NESP) for the treatment of anaemia in patients receiving multicycle chemotherapy. $\mathrm{Br} J$ Cancer 2001:84(suppl 1):17-23.

10 Smith RE Jr, Jaiyesimi IA, Meza LA, et al. Novel erythropoietic stimulating protein (NESP) for the treatment of anaemia of chronic disease associated with cancer. Br J Cancer 2001;84(suppl 1):24-30.

11 Silva M, Grillot D, Benito $A$, et al. Erythropoietin can promote erythroid progenitor survival by repressing apoptosis through $\mathrm{Bcl}-\mathrm{XL}$ and $\mathrm{Bcl}-2$. Blood 1996:88:1576-82.

12 Huraib S, Abu-Aisha $\mathrm{H}$, al-Momen $\mathrm{A}$, et al. Effect of recombinant human erythropoietin on lymphocyte phenotyping and phagocyte activity in hemodialysis patients. Am J Kidney Dis 1997;29:866-70.
13 Tilbrook PA, Klinken SP. The erythropoietin receptor. Int J Biochem Cell Biol 1999:31:1001-5

14 Macdougall IC. Meeting the challenges of a new millennium: optimising the use of recombinant human erythropoietin. Nephrol Dial Transplant 1998;13(suppl 2):23-7

15 Johnson CA, Wakeen M, Taylor CA, et al. Comparison of intraperitoneal and subcutaneous epoetin alfa in peritoneal dialysis patients. Perit Dial Int 1999;19:578-82.

16 Deputy Chief Medical Officer. Eprex® (epoetin alfa) and pure red cell aplasia-contraindication of subcutaneous administration to patients with chronic renal disease. London: Medical Control Agency, December 2002.

17 Eschbach JW. Erythropoietin: the promise and the facts. Kidney Int 1994;45(suppl 44):S70-6.

18 Mocks J. Cardiovascular mortality in haemodialysis patients treated with epoetin beta-a retrospective study. Nephron 2000:86:455-62.

19 Silverberg J, Rahal D, Pattin R, et al. Role of anaemia in the pathogenesis of left ventricular hypertrophy in end stage renal disease. Am J Cardiol 1989;64:222-4.

20 Muirhead N, Bargman J, Burgess E et al. Evidence-based recommendations for the clinical use of recombinant human erythropoietin. Am J Kidney Dis 1995;26/suppl 1):S1-24.

21 Jungers $\mathbf{P}$, Choukroun $G$, Oualim Z, et al. Beneficial influence of recombinant human erythropoietin therapy on the rate of progression of chronic renal failure in predialysis patients. Nephrol Dial Transplant 2001; 16:307-12

22 Cody J, Daly C, Campbell M, et al. Recombinant human erythropoietin for chronic renal failure anaemia in pre-dialysis patients (Cochrane review). Cochrane Database System Review 2001;4:CD003266.

23 Eknoyan G. The importance of early treatment of anemia of chronic kidney disease. Nephrol Dial Transplant 2001;16(suppl 5):45-9.

24 Silverberg DS, Blum M, Agbaria Z, et al. The effect of iv iron alone or in combination with low-dose erythropoietin in the rapid correction of anemia of chronic renal failure in the predialysis period. Clin Nephrol 2001;55:212-9.

25 Chapman JR. Blood transfusion policy. In: Catto GRD, ed. New clinical application nephrology: transplantation. London: Kluwer Academic Publication, 1989: 1-38.

26 Zaoui P, Boyle F, Mayrizi J, et al. Early thrombosis in kidney grafted into patients treated with erythropoietin. Lancet 1988;ii:956.

27 Wahlberg J, Jacobsson J, Odlind B, et al. Hemodilution in renal transplantation in patients on eryhtropoietin. Lancet 1988;ii: 1418

28 Muirhead N. Erythropoietin and renal transplantation. Kidney Int 1999;69(suppl):86-92.

29 Linde T, Ekberg H, Forslund T, et al. The use of pretransplant erythropoietin to normalise hemoglobin level: no deleterious effects on renal transplantation outcome. Transplantation 2001;71:79-82.

30 Strauss RG. Erythropoietin and neonatal anaemia. N Engl J Med 1994:330: 1227-8

31 Obladen M, Maier RF. Recombinant erythropoietin for prevention of anaemia in pre- term infants. Journal of Perinatal Medicine 1995;23: 1 19-26.

32 Reiter PD, Rosenberg AA, Valuck RJ. Factors associated with successful epoetin alfa therapy in premature infants. Ann Pharmacother 2000:34:433-9.

33 Franz AR, Pohlandt F. Red blood cell transfusions in very and extremely low birthweight infants under restrictive transfusion guidelines: is exogenous erythropoietin necessary? Arch Dis Child Fetal Neonatal Ed 2001;84:F96-100

34 Meyer MP. Anaemia of prematurity. Epidemiology, management and costs. Pharmacoeconomics 1997; 12:438-45.

35 Schefels J, Merz U, Hornchen H. Die Prophylaxe der Fruhgeborenenanamie mit rekombinantem humanen Erythropoietin: eine Kosten-Nutzen-analyse. Z Geburtshilfe Neonatol 1999;203/suppl 2): $1-5$

36 Ledbetter DJ, Juul SE. Erythropoieitn and the incidence of necrotising enterocolitis in infants with very low birth weight. J Pediatr Surg 2000;35:178-81.

37 Griffiths G, Lall R, Chatfield S, et al. Randomised controlled double blind study of role of recombinant erythropoietin in the prevention of chronic lung disease. Arch Dis Child Fetal Neonatal Ed 1997;76:F190-2.

38 Soubasi V, Kremenopoulos G, Tsantali C, et al. Use of erythropoietin and its effect on blood lactate and 2,3-diphosphoglycerate in premature neonates. Biol Neonate 2000;78:281-7.

39 Spivak JL. Recombinant human erythropoietin and the anaemia of cancer. Blood 1994:84:997-1004.

40 Hamasaki N, Yamamoto M. Red blood cell function and blood storage. Vox Sang 2000;79:191-7.

41 van Bommel J, de Korte D, Lind A, et al. The effect of the transfusion of stored RBCs on intestinal microvascular oxygenation in the rat. Transfusion 2001;41:1515-23.

42 Fernandes CJ Jr, Akamine N, de Marco FVC, et al. Red blood cell transfusion does not increase oxygen consumption in critically ill septic patients. Crit Care 2001;5:362-7.

43 Regan FA, Hewitt P, Barbara JA, et al. Prospective investigation of transfusion transmitted infection recipients of over 200,000 units of blood. TTI Study Group. BN 2000;320:403-6.

$44 \mathrm{McCullough}$ J. Complications of transfusion. In: McCullough J, ed Transfusion medicine. New York: McGraw-Hill, 1998: 337-60.

45 Vamvakas EC. Allogeneic blood transfusion as a risk factor for the subsequent development of non-Hodgkin's lymphoma. Transfus Med Rev 2000;14:258-68 
46 Beatty C. Autologous transfusion. In: Murphy MF, Pamphilon DH, eds. Practical transfusion medicine UK. Blackwell Science, 2001: 263-75. 47 Roback JD. CMV and blood transfusion. Reviews in Medical Virology 2002;12:211-9.

48 Miller CB, Jones RJ, Piantadosi S, et al. Decreased erythropoietin response in patients with the anemia of cancer. N Engl J Med 1990;322: 1689-92.

49 Mittelman M, Neumann D, Peled A, et al. Erythropoietin induces tumor regression and antitumor immune responses in murine myeloma models. Proc Natl Acad Sci U S A 2001:98:5181-6.

50 Case DC Jr, Bukonski RM, Carey RW, et al. Recombinant human erythropoietin therapy for anemia cancer patients on combination therapy. J Natl Cancer Inst 1993;85:801-6.

51 Casinu S, Fedeli A, Del Ferro E, et al. Recombinant human erythropoietin in cisplatin-associated anemia: a randomised double-blinded trial with placebo. J Clin Oncol 1994:12:1058-62.

52 Del Mastro L, Venturini M, Lionetoo R, et al. Randomised phase III trial evaluating the role of erythropoietin in the prevention of chemotherapy-induced anemia. J Clin Oncol 1997; 15:2715-21.

53 ten Bokkel Huinink WW, de Swart CA, van Toorn DW, et al. Controlled multicenter study of the influence of subcutaneous recombinant erythropoietin on anemia and transfusion dependency in patients with ovarian carcinoma treated with platinum-based chemotherapy. Med Oncol 1998; 15:174-82.

54 Nowrousian MR. Recombinant human erythropoietin in the treatment of cancer related or chemotherapy-induced anemia in patients with solid tumors. Med Oncol 1998;15(suppl 1):S19-28.

55 Demetri GD, Kris M, Wade J, et al. Quality-of-life benefit in chemotherapy patients treated with epoetin-alfa is independent of disease response or tumor type results from a prospective community oncology study, Procrit Study Group. J Clin Oncol 1998;16:3412-25.

56 Littlewood TJ. The impact of hemoglobin levels on treatment outcomes in patients with cancer. Semin Oncol 2001;28(2 suppl 8):49-53.

57 Antonadou D, Cardamakis E, Puglisi M, et al. Erythropoietin enhances radiation treatment efficacy in patients with pelvic malignancies. Final results of a randomised phase III study. Eur J Cancer 2001;37/suppl 6): 144.

58 Crawford J, Cella D, Cleeland CS, et al. Relationship between changes in haemoglobin level and quality of life during chemotherapy in anemic cancer patients receiving epoetin alfa therapy. Cancer 2002;95:888-95

59 Rose E, Rai K, Revicki D, et al. Clinical and health states assessment in anemic chronic lymphatic leukaemia (CLL) patients treated with epoetin alfa (epo). Journal of the American Society of Hematology 1994;84:526a.

60 Cazzola M, Messinger D, Battistel V, et al. Recombinant human erythropoietin in the anemia associated with multiple myeloma or non-Hodgkin's lymphoma: dose finding and identification of the predictors of response. Blood 1995:86:4446-53.

61 Osterborg A, Boogaerts MA, Cimino R, et al. Recombinant human erythropoieitn in transfusion-dependent anaemic patients with multiple myeloma and non-Hodgkin's lymphoma-a randomised multicentre study. Blood 1996;87:2675-82.

62 Dammaco F, Silvestris F, Castoldi GL, et al. The effectiveness and tolerability of epoetin alfa in patients with multiple myeloma refractory to chemotherapy. Int I Clin Lab Res 1998;28:127-34.

63 Hellstrom-Lindberg E. Efficacy of erythropoietin in the myelodysplastic syndrome:a meta-analysis of 205 patients from 17 studies. BrJ Haematol 1995;89:67-71.

64 Hellstrom-Lindberg E, Negria R, Stein R, et al. Erythroid response to treatment with G-CSF plus erythropoietin for the anemia of patients with myelodysplastic syndrome: proposals of a predictive model. $\mathrm{Br}$ myelodysplastic syndrome: prop

65 Hast R, Wallvik J, Folin A. Long-term follow-up of 18 patients with myelodysplastic syndrome responding to recombinant erythropoietin treatment. Leuk Res 1999;25:13-8.

66 Pihlstedt P, Paulin T, Sundberg B, et al. Blood transfusion in marrow graft recipients. Ann Hematol 1992;65:66-70.

67 Klaesson S. Clinical use of rHuEPO in bone marrow transplantation. Med Oncol 1999:16:2-7

68 McCullough J. Autologous blood donation and transfusion. In: McCullough J, ed. Transfusion medicine. New York: McGraw-Hill, Health Professions Division, 1998: 99-118.

69 Yazicioglu L, Eryilmaz S, Sirlak M, et al. Recombinant human erythropoietin administration in cardiac surgery. J Cardiothorac Surg 2001:122:741-5.

70 Stovall TG. Clinical experience with epoetin alfa in the management of hemoglobin levels in orthopedic surgery and cancer. Implication for use in gynecologic surgery. J Reprod Med 2001;46(5 suppl):531-8.

71 Wurnig C, Schatz K, Noske H, et al. Subcutaneous low-dose epoetin beta for the avoidance of transfusion in patients scheduled for elective surgery not eligible for autologous blood donation. Eur Surg Res 2001;33:303-10

72 Henry DH, Beall GN, Benson CA, et al. Recombinant human erythropoietin in the treatment of anemia associated with huma immunodeficiency virus (HIV) infections and zidovudine therapy. Overview of four clinical trials. Ann Intern Med 1992;117:739-48.
73 Phair JP, Abels RI, McNeill MV, et al. Recombinant human erythropoietin treatment: investigational new drug protocol for the anemia of the acquired immunodeficiency syndrome. Arch Intern Med anemia of the acquired in
1993; 153:2669-75.

74 Moore RD, Keruly JC, Chaisson RE. Anemia and survival in HIV infection. J Acquir Immune Defic Syndr Hum Retrovirol 1998;19:29-33.

75 Volberding P. Consensus statement: anemia in HIV infection-current trend in treatment options, and practice strategies. Anemia in HIV Working Group. Clin Ther 2000;22:1004-20.

76 Peeters HR, Jongen-Lavrencic $M$, Bakkar $\mathrm{CH}$, et al. Recombinant human erythropoietin improves health-related quality of life in patients with rheumatoid arthritis and anaemia of chronic disease; utility measures correlate strongly with disease activity measures. Rheumatol Int 1999;18:201-6.

77 Linardaki GD, Boki KA, Fertakis A, et al. Pure red cell aplasia as presentation of systemic lupus erythematosus:antibodies to erythropoietin. Scand I Rheumatol 1999:28:189-91.

78 Christodoulou DK, Tsianos EV. Anemia in inflammatory bowel disease - the role of recombinant erythropoietin. European Journal of Internal Medicine 2000;1 1:222-7.

79 Tchernia G, Delhommeau F, Perrotta S, et al. Recombinant erythropoietin therapy as an alternative to blood transfusion in infants with hereditary spherocytosis. Hematology Journal 2000;1:146-52.

80 Shapira Y, Bairey O, Vatury $M$, et al. Erythropoieitin can obviate the need for repeated heart valve replacement in high-risk patients with severe mechanical haemolytic anemia: case reports and literature review. $J$ Heart Valve Dis 2001; 10:431-5.

81 Rachmilewitz EA, Aker $M$. The role of recombinant human erythropoietin in the treatment of thalassemia. Ann N Y Acad Sci 1998;850: 129-38

82 Nemoto T, Yokota N, Keane WF, et al. Recombinant erythropoietin rapidly treats anemia in ischemic acute renal failure. Kidney Int 2001;59:246-51

83 Westenfelder C. Unexpected renal actions of erythropoietin. Exp Nephrol 2002;10:294-8.

84 Bagnis C, Beaufils $\mathrm{H}$, Jacquiaud C, et al. Erythropoietin enhances recovery after cisplatin-induced acute renal failure in the rat. Nephrol Dial Transplant 2001:16:932-8.

85 Kurt E, Evrensel T, Dilek K, et al. Effects of two different doses of recombinant human erythropoietin ( $r$-HuEPO) on cisplatin-induced acute renal failure. Proceedings of the American Society of Clinical Oncology 2002 (abst 1842)

86 van Iperen CE, Gaillard CA, Kraaijenhagen RJ, et al. Response of erythropoiesis and iron metabolism to recombinant human erythropoietin in intensive care unit patients. Crit Care Med 2000;28:2773-8.

87 Corwin HL, Gettinger A, Rodriguez RM, et al. Efficacy of recombinant human erythropoietin in the critically ill patients: a randomised, double-blind, placebo-controlled trial. Crit Care Med 1999;27:234650 .

88 Cerami A. Beyond erythropoiesis: novel applications for recombinant human erythropoietin. Semin Hematol 2001;38(3 suppl 7):33-9.

89 Gorio A, Gokmen N, Erbayraktar S, et al. Recombinant human erythropoietin counteracts secondary injury and markedly enhances neurological recovery experimental spinal cord trauma. Proc Natl Acad Sci U S A 2002;99:9450-5

90 Ehrenreich $H$, Hasselblatt $M$, Dembowski $C$, et al. Erythropoietin therapy for acute stroke is both safe and beneficial. Mol Med 2002;8:495-505

91 Silverberg DS, Wexler D, laina A. The importance of anemia and its correction in the management of severe congestive heart failure. European Journal of Heart Failure 2002:4:681-6.

92 Silverberg DS, Wexler D, Blum M, et al. The effect of correction of anaemia in diabetes and non-diabetes with severe resistant congestive heart failure and chronic renal failure by subcutaneous erythropoietin and intravenous iron. Nephrol Dial Transplant 2003;18:141-6.

93 Robinson A, ed. Blood matters. Quarterly information for hospitals served by the National Blood Service. UK: National Blood Service, September 2001 (issue 8).

94 Chikada M, Furuse A, Kotsuka Y, et al. Open-heart surgery in Jehovah's Witness patients. Cardiovasc Surg 1996;4:311-4.

95 Nelson CL, Stewart JG. Primary and revision total hip replacement in patients who are Jehovah's Witnesses. Clin Orthop 1999;369:251-6

96 Busuttil D, Copplestone A. Management of blood loss in Jehovah's Witnesses. BM 1995;311:1115-6.

97 Ekblom BT. Blood boosting and sport. Baillieres Clin Endocrinol Metab 2000;14:89-98.

98 Bolanos L, Castro P, Falcon TG, et al. Continuous intravenous sodium ferric gluconate improves efficacy in the maintenance phase of EPOrHu administration in hemodialysis patients. Am J Nephrol 2002;22:67-72.

99 Casadevall N, Nataf J, Viron B, et al. Pure red-cell aplasia and antierythropoietin antibodies in patients treated with recombinant erythropoietin. N Engl J Med 2002;346:469-75

100 Gershon SK, Luksenburg H, Cote TR, et al. Pure red-cell aplasia and recombinant erythropoietin. N Engl J Med 2002;346:1584-5.

101 Casadevall N, Mayeux P. Pure red-cell aplasia and recombinan erythropoietin. N Engl J Med 2002;346:1585.

102 Casadevall N. Antibodies against r-HuEPO: native and recombinant. Nephrol Dial Transplant 2002;17(suppl 5):42-7. 